\title{
Do Cytokines Play a Role in Predicting Some Features and Outcome in Infective Endocarditis?
}

\author{
Maria Carmo Pereira Nunes ${ }^{1 *}$, Izabella Rodrigues de Araújo ${ }^{1}$, Andréa Teixeira de Carvalho ${ }^{2}$, \\ Letícia Alves Andrade ${ }^{1}$, Marcio Henrique Lima Resende ${ }^{1}$, José Luiz Padilha da Silva ${ }^{3}$, \\ Teresa Cristina Abreu Ferrari ${ }^{1}$
}

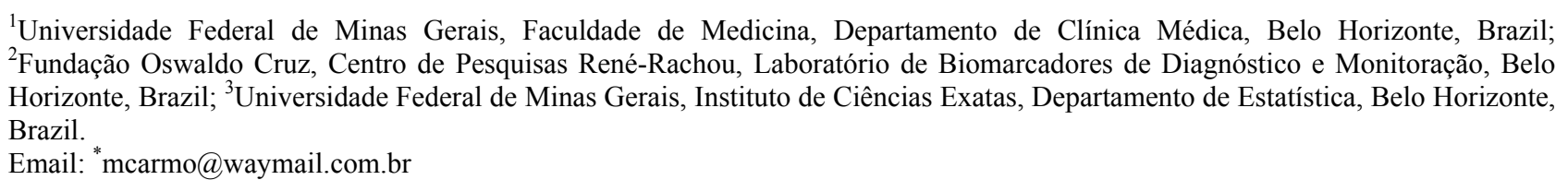

Received February $28^{\text {th }}, 2013$; revised March $28^{\text {th }}, 2013$; accepted April $28^{\text {th }}, 2013$

Copyright (C) 2013 Maria Carmo Pereira Nunes et al. This is an open access article distributed under the Creative Commons Attribution License, which permits unrestricted use, distribution, and reproduction in any medium, provided the original work is properly cited.

\begin{abstract}
Objective: This study aimed to measure the serum concentrations of several cytokines in patients with infective endocarditis (IE), and correlate them with the C-reactive protein serum levels, echocardiographic findings and infecting microorganisms. Methods: Forty-five patients with definite IE according to the Duke's criteria were included in the study. Ten healthy blood donors formed the control group. Serum levels of interleukin (IL) $1 \beta$, IL-6, IL-8, IL-10, IL-12 and tumor necrosis factor- $\alpha(\mathrm{TNF}-\alpha)$ were measured and compared between the groups, and also with some clinical and laboratory parameters of IE. Results: Patients with IE had significantly higher serum concentrations of the inflammatory mediators than the control patients. Median IL-12 and IL-1 $\beta$ levels were higher in staphylococcal than streptococcal IE. Except for TNF- $\alpha$, the levels of all the other cytokines correlated with the C-reactive protein concentrations. In multivariate analysis, IL-10 and IL-12 serum levels remained as independent factors associated with the C-reactive protein concentrations. There was a significant correlation between IL-10 concentration and vegetation length. Conclusion: The inflammatory serum cytokines levels were elevated in IE in comparison to healthy controls. C-reactive protein concentrations correlated with cytokines levels. IL-1 $\beta$ and IL-12 serum concentrations were higher in staphylococcal when compared to streptococcal IE. IL-10 levels were associated with vegetation size.
\end{abstract}

Keywords: Infective Endocarditis; Inflammatory Cytokines; C-Reactive Protein

\section{Introduction}

Infective endocarditis (IE) remains a severe disease associated with a high mortality rate despite recent advances in its diagnosis and treatment [1-4]. This disorder presents in a variety of clinical forms according to the initial clinical manifestation, underlying cardiac disease, microorganism involved, and development of complications [5]. Currently, the presentation of IE has changed throughout the world, with a reduction in the classic clinical findings traditionally associated with this condition, which can make its diagnosis difficult $[2,6]$. Several factors affect outcome in IE. The infecting microorganism and diagnostic delay are well-known determinants of the outcome [7,8]. Echocardiography plays a known key

${ }^{*}$ Corresponding author. role in the diagnosis of this condition, but echocardiograph findings should be interpreted taking into account the clinical features $[9,10]$. Blood cultures pose an inherent delay, which may contribute to the high morbidity and mortality rates traditionally observed in patients suffering from blood culture-negative endocarditis [11]. Considering the infective-inflammatory nature of IE, it is possible to suggest that serum inflammatory markers may contribute to the diagnosis and management of this condition $[4,12]$. Cytokines are small peptides produced when sensitized lymphocytes come directly into contact with an antigen; therefore, they are elevated in a number of conditions such as infectious processes, burns and other inflammatory disorders as part of the systemic inflammatory response [4,11-17]. Thus, considering the 
potential use of these immune system molecules in diagnosing and monitoring IE, we measured the serum concentrations of several inflammatory cytokines in a group of patients with IE, and correlated them with the C-reactive protein levels, echocardiographic findings, and infecting microorganisms.

\section{Methods}

\subsection{Patient Population}

From September 2005 to July 2010, 101 consecutive patients with definite IE according to the Duke's criteria [18] were admitted to the University Hospital, Federal University of Minas Gerais, Belo Horizonte, Brazil. Serum samples from 45 of these patients were obtained to assess the concentrations of some cytokines (see below). Written informed consent was obtained from all the patients, as required by the institutional Ethics Committee.

Transthoracic (TTE) and/or transesophageal echocardiography (TEE), as clinically indicated, were performed as previously described [10]. The presence and characteristics of the following findings were investigated: vegetation, abscess, new dehiscence, and new moderate or severe valvular regurgitation. Blood cultures, complete blood count, serum C-reactive protein levels, serum chemistry and urine analysis comprised the routine laboratory investigations that were recorded. Serum samples, obtained within the first 72 hours of admission, were analyzed for the following markers: interleukin (IL) $1 \beta$, IL-6, IL-8, IL-10, IL-12 and tumor necrosis factor- $\alpha$ $(\mathrm{TNF}-\alpha)$. Serum samples from 10 healthy blood donors (control group) were also assayed. Cytokine concentrations were measured by cytometric bead array.

\subsection{Cytometric Bead Array Assay}

The cytometric bead array (CBA) kit (Becton Dickinson [BD], Pharmingen, San Diego, USA) was used for quantitative analysis of serum cytokines following the instructions of the manufacturer, and as previously described. [19] Briefly, a mixture of beads specific for the human cytokines-IL-1 $\beta$, IL-6, IL-8, IL-10, IL-12 and TNF- $\alpha$ with distinct fluorescent intensities (in the FL-3 channel) were coated with capture antibodies specific for each cytokine. A second fluorescently labeled PE-anti-cytokine antibody was added, and the concentrations of the individual cytokines were indicated by their fluorescent intensity. Data were acquired using a FACScalibur flow cytometer (Becton Dickinson, USA). BD CBA software (Becton Dickinson, USA) was used for sample analysis. The results were based on standard concentration curves and expressed as $\mathrm{pg} / \mathrm{ml}$.

\subsection{Statistical Analysis}

Data were summarized as means \pm standard deviation
(SD), medians and interquartile range or proportions. All data sets were non-Gaussian in distribution and non-parametric analyses were used to compare the median concentrations of each cytokine. Cytokines associated with Creactive protein were identified by univariate linear regression analysis, and multivariate analysis was performed to identify the cytokines with a significant independent relationship to C-reactive protein. The analyses were performed using SPSS statistical software (version 18.0; SPSS, Chicago, IL).

\section{Results}

Forty-five patients with IE diagnosed according to the Duke's criteria (major and/or minor) were included in the study. Mean age was $42 \pm 16$ years (range, 15 - 76 years), and $23(51 \%)$ individuals were male. The main causative microorganisms were staphylococci, streptococci, and enterococci. Early surgery was performed in $12(27 \%)$ cases, and $10(22 \%)$ patients died. Patients with IE had significantly higher serum concentrations of the inflammatory mediators than the control patients' serum (Table 1). Infecting microorganisms were isolated from 26 patients $(58 \%)$. There were no significant differences of cytokine concentrations between patients with positive and negative blood cultures.

In order to assess the levels of the cytokines according to the infecting microorganism, the patients were stratified on the basis of staphylococcal or streptococcal IE (Table 2). Median IL-12 serum levels were higher in the cases of staphylococcal IE $(87 \mathrm{pg} / \mathrm{ml}$; range $36-708$ $\mathrm{pg} / \mathrm{ml})$ than in those of IE caused by streptococci (43 $\mathrm{pg} / \mathrm{ml}$; range $31-224 \mathrm{pg} / \mathrm{ml} ; p=0.023)$. Likewise, IL-1 $\beta$ serum concentrations were higher in the patients with staphylococcal IE $(95 \mathrm{pg} / \mathrm{ml}$; range $56-197 \mathrm{pg} / \mathrm{ml})$ in comparison with those with streptococcal IE $(65 \mathrm{pg} / \mathrm{ml}$; range $49-263 \mathrm{pg} / \mathrm{ml} ; p=0.019)$.

C-reactive protein serum concentrations did not differ significantly regarding the microorganisms. There was no correlation between leukocyte counts and serum concentrations of the cytokines. Except for TNF- $\alpha$, the levels of all the other cytokines correlated with the C-reactive protein serum concentrations: IL-12 correlated negatively; and the other cytokines, positively (Table 3 ). At multivariate analysis, IL-10 and IL-12 concentrations remained as independent factors associated with the C-reactive protein levels in the group of patients with IE. There were not any significant differences in the serum levels of all the cytokines analyzed, when the patients who died or needed valvular surgery were compared to those successfully treated with antibiotics alone. However, a significant positive correlation was observed between IL-10 concentrations and vegetation length assessed by echocardiography $(r=0.44 ; p=0.016)$. No other association was found between the cytokine serum 
Table 1. Median serum concentrations of the measured inflamatory cytokines in the IE and control patients.

\begin{tabular}{cccc}
\hline Cytokines $^{*}$ & Patients $(n=45)$ & Controls $(n=10)$ & $P$ value \\
\hline IL-6 $(\mathrm{pg} / \mathrm{ml})$ & $223[135-373]$ & $32[0-322]$ & 0.006 \\
IL-8 $(\mathrm{pg} / \mathrm{ml})$ & $334[172-531]$ & $184[112-289]$ & 0.040 \\
IL-10 $(\mathrm{pg} / \mathrm{ml})$ & $74[61-91]$ & $0[0-12]$ & $<0.001$ \\
IL-12 $(\mathrm{pg} / \mathrm{ml})$ & $62[48-122]$ & $6[0-8]$ & $<0.001$ \\
TNF- $\alpha(\mathrm{pg} / \mathrm{ml})$ & $52[44-69]$ & $0[0-47]$ & 0.001 \\
IL-1 $\beta(\mathrm{pg} / \mathrm{ml})$ & $86[63-126]$ & $0[0-222]$ & 0.006 \\
\hline
\end{tabular}

IE-infective endocarditis; IL-interleukin.

Table 2. Median serum concentrations of the measured inflammatory cytokines in the IE patients for different groups of infecting microorganisms.

\begin{tabular}{cccc}
\hline Cytokines $^{*}$ & Staphylococci $(n=45)$ & Streptococci $(n=10)$ & $p$ value \\
\hline IL-6 $(\mathrm{pg} / \mathrm{ml})$ & $177[115-401]$ & $133[85-295]$ & 0.412 \\
IL-8 $(\mathrm{pg} / \mathrm{ml})$ & $310[171-505]$ & $204[135-503]$ & 0.818 \\
IL-10 $(\mathrm{pg} / \mathrm{ml})$ & $77[62-90]$ & $76[62-122]$ & 0.895 \\
IL-12 $(\mathrm{pg} / \mathrm{ml})$ & $87[58-197]$ & $43[38-60]$ & 0.023 \\
TNF- $\alpha(\mathrm{pg} / \mathrm{ml})$ & $66[60-80]$ & $51[43-64]$ & 0.131 \\
IL-1 $\beta(\mathrm{pg} / \mathrm{ml})$ & $95[80-125]$ & $65[62-71]$ & 0.019 \\
\hline
\end{tabular}

*Values are expressed as median (inter-quartile range).

Table 3. Correlation between serum cytokine and C-reactive protein concentrations in the IE patients.

\begin{tabular}{ccc}
\hline Cytokines $^{*}$ & $r$ & $P$ value \\
\hline IL-6 $(\mathrm{pg} / \mathrm{ml})$ & 0.280 & 0.044 \\
IL-8 $(\mathrm{pg} / \mathrm{ml})$ & 0.335 & 0.020 \\
IL-10 $(\mathrm{pg} / \mathrm{ml})$ & 0.418 & 0.004 \\
IL-12 $(\mathrm{pg} / \mathrm{ml})$ & -0.347 & 0.016 \\
TNF- $\alpha(\mathrm{pg} / \mathrm{ml})$ & 0.194 & 0.121 \\
IL-1 $\beta(\mathrm{pg} / \mathrm{ml})$ & 0.219 & 0.094 \\
\hline
\end{tabular}

IE-infective endocarditis; r-correlation coefficient; IL-interleukin.

levels and each of the different echocardiographic parameters evaluated or valve involved.

\section{Discussion}

The pathogenesis of IE involves the formation of septic vegetation and inflammatory reaction in the infected valves or adjacent endocardium $[8,20]$. Several cytokines are essential for initiating and maintaining the inflammatory response by recruiting leukocytes to the sites of infection $[4,8,12,16,17]$. The present study confirmed that proinflammatory cytokines are elevated in serum from IE patients compared to health subjects. Correlations between serum levels of cytokines and C-reactive protein were also observed. There was a positive correlation between IL-10 concentration and vegetation length. Fur- thermore, IL-1 $\beta$ and IL-12 serum levels were considerably higher in staphylococcal than streptococcal IE.

Major predisposing conditions for the development of IE are the presence of a cardiac platelet-fibrin vegetation and circulating bacteria with relatively low susceptibility to microbicidal activity of blood platelets [15]. Inflamed endothelia produce cytokines, integrins and tissue factor, which, in turn, attract fibronectin, monocytes, and platelets. Bacteria attaching to such structures further activate the inflammatory cascade, becoming embedded and protected from the host defenses. The intensity of inflammation and tissue destruction may vary depending on bacterial species and distribution of the inflammatory infiltrate [9]. Persistent or recurrent inflammation induced by residual septic vegetations after antibiotic therapy may lead to valve damage, which is one of the most severe complications of IE.

Recent appreciation of the specific roles of some cytokines in inflammation has allowed further understanding of some pathophysiological findings of IE. Previous studies showed that serum levels of inflammatory cytokines are elevated in IE patients, and decrease after the initiation of antimicrobial treatment. Rawzczynska-Englert [21] demonstrated that in the control patients with urinary tract infections, serum IL-6 titers were elevated, but not as high as those observed in the patients with IE. However, differently from our results, the levels of TNF$\alpha$ were not elevated in the IE patients. In another investigation[17], serum TNF- $\alpha$ concentrations were measured in streptococcal IE; and with the exception of the "complexes" cases, this cytokine was undetectable. The differences in TNF- $\alpha$ detection observed between these studies and ours may be, at least partially, to the higher sensitivity of the technique employed in our investigation. TNF- $\alpha$ is a potent proinflammatory cytokine that can stimulate chemokine production by endothelial cells and fibroblasts in vitro [22]. In the present study, IE patients had significantly higher serum concentrations of the measured cytokines than the control subjects. Additionally, there was a positive correlation between the concentrations of most evaluated cytokines and the C-reactive protein levels, suggesting that the overproduction of these inflammatory markers correlates with the inflammatory activity. Curiously, although the TNF- $\alpha$ levels were elevated, they did not correlate with the $\mathrm{C}$-reactive protein concentrations.

Alter et al. [12] measured the levels of IL-2 receptor (IL-2R) and IL-6 in serum from 47 patients with IE. Both molecules were elevated prior treatment and decreased during antibiotic administration. IL-2R and IL-6 titers were also high in culture negative IE cases. Similarly, in our study, the concentrations of the cytokines were significantly elevated in IE independently of the status of the blood cultures.

Although streptococcal and Staphylococcus aureus IE 
share the same primary site of infection, their pathogenesis and clinical evolution have several major differences. Streptococci adhere to the cardiac valves with pre-existing endothelial lesions. In contrast, $S$. aureus is able to colonize damaged endothelium or invade physically intact endothelial cells [8]. S. aureus is associated with both a higher rate of complications and mortality in IE. We found that IL-12 serum concentrations were higher in patients with endocarditis caused by $S$. aureus compared with streptococcal IE. This finding is in agreement with the observation that pathogens can differ in their abilities to induce inflammatory and immunoregulatory cytokines [4]. This may be due to the more virulent nature of $S$. aureus, which in turn causes IE of more aggressive course. It remains uncertain whether initial high cytokine titers are associated (or not) with a worse prognosis.

An effective host defense against bacterial invasion is characterized by a vigorous recruitment and activation of inflammatory cells, which are modulated by the coordinated expression of both pro- and anti-inflammatory cytokines. Various organisms can initiate cell mediated immunity by stimulating macrophages to produce IL- 12 . IL-10 inhibits gamma-interferon (IFN- $\gamma$ ) synthesis, and therefore the production of proinflammatory cytokines such as IL-12 and TNF- $\alpha$. The inhibiting effects of IL-10 on cytokine production correlate with their antiinflammatory effects in vivo [16]. Thus, it would be expected an inverse relation between vegetation size and serum IL-10 concentrations, which is the opposite of what was observed in our study. It is difficult to explain this finding, as in addition to the important and cross-regulatory roles of IL-10, IFN- $\gamma$, IL-12 and TNF- $\alpha$ in infection [14], the immune process in IE is very complex and several factors may be involved.

\section{Conclusion}

The proinflammatory cytokines were elevated in the IE in comparison to healthy controls. C-reactive protein levels correlated with cytokines. IL-1 $\beta$ and IL-12 serum concentrations were considerably higher in staphylococcal when compared to streptococcal IE. IL-10, which has antiinflammatory effects, was positively correlated with the size of the vegetation. The role of serum cytokine concentrations as predictors of outcome in IE remains unclear.

\section{Acknowledgements}

We thank all the personal of the echocardiography and laboratory for their collaboration throughout the study.

\section{REFERENCES}

[1] V. H. Chu, C. H. Cabell, D. K. Benjamin Jr., E. F.
Kuniholm, V. G. Fowler Jr., J. Engemann, D. J. Sexton, G. R. Corey and A. Wang, "Early Predictors of In-Hospital Death in Infective Endocarditis," Circulation, Vol. 109, No. 14, 2004, pp. 1745-1749. doi:10.1161/01.CIR.0000124719.61827.7F

[2] D. R. Murdoch, G. R. Corey, B. Hoen, J. M. Miro, V. G. Fowler Jr., A. S. Bayer, A. W. Karchmer, L. Olaison, P. A. Pappas, P. Moreillon, S. T. Chambers, V. H. Chu, V. Falco, D. J. Holland, P. Jones, J. L. Klein, N. J. Raymond, K. M. Read, M. F. Tripodi, R. Utili, A. Wang, C. W. Woods and C. H. Cabell, "Clinical Presentation, Etiology, and Outcome of Infective Endocarditis in the 21st Century: The International Collaboration on EndocarditisProspective Cohort Study," Archives of Internal Medicine, Vol. 169, No. 5, 2009, pp. 463-473.

doi:10.1001/archinternmed.2008.603

[3] M. A. Costa, D. R. Wollmann Jr., A. C. Campos, C. L. Cunha, R. G. Carvalho, D. F. Andrade and D. R. Loures, "Risk Index for Death by Infective Endocarditis: A Multivariate Logistic Model," Revista Brasileira de Cirurgia Cardiovascular, Vol. 22, No. 2, 2007, pp. 192-200.

[4] Y. Jiang, L. Magli and M. Russo, "Bacterium-Dependent Induction of Cytokines in Mononuclear Cells and Their Pathologic Consequences in Vivo," Infection and Immunity, Vol. 67, No. 5, 1999, pp. 2125-2130.

[5] J. C. Castillo, M. P. Anguita, M. Ruiz, L. Pena, M. Santisteban, M. Puentes, J. M. Arizon and J. Suarez de Lezo, "Changing Epidemiology of Native Valve Infective Endocarditis," Revista Española de Cardiología, Vol. 64, No. 7, 2011, pp. 594-598.

[6] F. Delahaye, "Is Early Surgery Beneficial in Infective Endocarditis? A Systematic Review," Archives of Cardiovascular Diseases, Vol. 104, No. 1, 2011, pp. 35-44. doi:10.1016/j.acvd.2010.11.003

[7] V. G. Fowler, Jr., L. L. Sanders, L. K. Kong, R. S. McClelland, G. S. Gottlieb, J. Li, T. Ryan, D. J. Sexton, G. Roussakis, L. J. Harrell and G. R. Corey, "Infective Endocarditis Due to Staphylococcus aureus: 59 Prospectively Identified Cases with Follow-Up," Clinical Infectious Diseasess, Vol. 28, No. 1, 1999, pp. 106-114. doi:10.1086/515076

[8] P. Moreillon, Y. A. Que and A. S. Bayer, "Pathogenesis of Streptococcal and Staphylococcal Endocarditis," Infectious Disease Clinics of North America, Vol. 16, No. 2, 2002, pp. 297-318. doi:10.1016/S0891-5520(01)00009-5

[9] M. C. Nunes, C. L. Gelape and T. C. Ferrari, "Profile of Infective Endocarditis at a Tertiary Care Center in Brazil during a Seven-Year Period: Prognostic Factors and InHospital Outcome," International Journal of Infectious Diseases, Vol. 14, No. 5, 2010, pp. e394-e398. doi:10.1016/j.ijid.2009.06.024

[10] G. Habib, L. Badano, C. Tribouilloy, I. Vilacosta, J. L. Zamorano, M. Galderisi, J. U. Voigt, R. Sicari, B. Cosyns, K. Fox and S. Aakhus, "Recommendations for the Practice of Echocardiography in Infective Endocarditis," European Journal of Echocardiography, Vol. 11, No. 2, 2010, pp. 202-219. doi:10.1093/ejechocard/jeq004

[11] M. Brown and G. E. Griffin, "Immune Responses in Endocarditis," Heart, Vol. 79, No. 1, 1998, pp. 1-2. 
[12] P. Alter, J. Hoeschen, M. Ritter and B. Maisch, "Usefulness of Cytokines Interleukin-6 and Interleukin-2R Concentrations in Diagnosing Active Infective Endocarditis Involving Native Valves," American Journal of Cardiology, Vol. 89, No. 12, 2002, pp. 1400-1404. doi:10.1016/S0002-9149(02)02353-6

[13] R. W. Watkin, L. V. Harper, A. B. Vernallis, S. Lang, P. A. Lambert, A. M. Ranasinghe and T. S. Elliott, "ProInflammatory Cytokines IL6, TNF-Alpha, IL1Beta, Procalcitonin, Lipopolysaccharide Binding Protein and CReactive Protein in Infective Endocarditis," Journal of Infection, Vol. 55, No. 3, 2007, pp. 220-225. doi:10.1016/j.jinf.2007.05.174

[14] G. Trinchieri, "Cytokines Acting on or Secreted by Macrophages during Intracellular Infection (IL-10, IL-12, IFNGamma)," Current Opinion in Immunology, Vol. 9, No. 1, 1997, pp. 17-23. doi:10.1016/S0952-7915(97)80154-9

[15] C. T. Shun, C. Y. Yeh, C. J. Chang, S. H. Wu, H. T. Lien, J. Y. Chen, S. S. Wang and J. S. Chia, "Activation of Human Valve Interstitial Cells by A Viridians Streptococci Modulin Induces Chemotaxis of Mononuclear Cells," The Journal of Infectious Diseases, Vol. 199, No. 10, 2009, pp. 1488-1496. doi:10.1086/598485

[16] L. Li, J. F. Elliott and T. R. Mosmann, "IL-10 Inhibits Cytokine Production, Vascular Leakage, and Swelling during T Helper 1 Cell-Induced Delayed-Type Hypersensitivity," The Journal of Immunology, Vol. 153, No. 9, 1994, pp. 3967-3978.

[17] W. V. Kern, A. Engel, S. Schieffer, O. Prummer and P. Kern, "Circulating Tumor Necrosis Factor Alpha (TNF),
Soluble TNF Receptors, and Interleukin-6 in Human Subacute Bacterial Endocarditis," Infection and Immunity, Vol. 61, No. 12, 1993, pp. 5413-5416.

[18] D. T. Durack, A. S. Lukes and D. K. Bright, "New Criteria for Diagnosis of Infective Endocarditis: Utilization of Specific Echocardiographic Findings. Duke Endocarditis Service," American Journal of Medicine, Vol. 96, No. 3, 1994, pp. 200-209. doi:10.1016/0002-9343(94)90143-0

[19] E. B. Cook, J. L. Stahl, L. Lowe, R. Chen, E. Morgan, J. Wilson, R. Varro, A. Chan, F. M. Graziano and N. P. Barney, "Simultaneous Measurement of Six Cytokines in a Single Sample of Human Tears Using MicroparticleBased Flow Cytometry: Allergics vs. Non-Allergics," Journal of Immunological Methods, Vol. 254, No. 1-2, 2001, pp. 109-118. doi:10.1016/S0022-1759(01)00407-0

[20] U. Allen, "Infective Endocarditis: Updated Guidelines," Canadian Journal of Infectious Diseases \& Medical Microbiology, Vol. 21, No. 2, 2010, pp. 74-77.

[21] I. Rawczynska-Englert, T. Hryniewiecki and D. Dzierzanowska, "Evaluation of Serum Cytokine Concentrations in Patients with Infective Endocarditis," Journal of Heart Valve Disease, Vol. 9, No. 5, 2000, pp. 705-709.

[22] I. Sylvester, J. A. Rankin, T. Yoshimura, S. Tanaka and E. J. Leonard, "Secretion of Neutrophil Attractant/Activation Protein by Lipopolysaccharide-Stimulated Lung Macrophages Determined by Both Enzyme-Linked Immunosorbent Assay and N-Terminal Sequence Analysis," American Review of Respiratory Disease, Vol. 141, No. 3, 1990, pp. 683-688. doi:10.1164/ajrccm/141.3.683 